\title{
Interação Idoso-Embalagem: Uma Reflexão Sobre a Ergonomia no Design de Embalagens
}

\author{
Elderly-Packaging Interaction: A Reflection about Ergonomics in Packaging Design
}

GIORDANI, Bianca Marina; Mestranda em Design; Universidade do Estado de Santa Catarina giordanibianca@gmail.com

CINELLI, Milton José; Doutor em Chimie Physique Option Matériaux; Universidade do Estado de Santa Catarina

milton.cinelli@udesc.br

\section{Resumo}

A população idosa vem crescendo, demandando produtos e serviços adequados às suas necessidades. Contudo, muitos artefatos não são apropriados para tais usuários, visto que características da terceira idade nem sempre são utilizadas nos projetos. Isso ocorre no setor de embalagens. Estudos recentes indicam que a manipulação de algumas embalagens exige aptidão que os idosos não possuem, restringindo o acesso aos produtos e causando prejuízos. Isso demonstra a importância da ergonomia no design de embalagens, para conhecer as capacidades dos sujeitos. Desse modo, o presente artigo propõe uma reflexão sobre ergonomia, embalagens e idosos, a partir de revisão teórica para fundamentar a temática e achados de pesquisas empíricas. Assim, pode-se observar como a ergonomia é relevante, sendo um conhecimento subutilizado na área, mas que deve ser cada vez mais aplicado no diagnóstico de problemas nas embalagens e para o projeto de dispositivos adequados as necessidades dos usuários, em especial idosos.

Palavras Chave: idosos; embalagens; ergonomia.

\begin{abstract}
The elderly population is growing, demanding products and services adapted to their needs. However, many artifacts are not appropriate for such users, the characteristics of old age are not always used in projects. It occurs in packaging industry. Recent studies indicate that the handling of some packaging requires aptitude that elderly do not have, restricting access to the products and causing damages. It demonstrates the importance of ergonomics in packaging design, in order to know the capacities of the users. The present article proposes a reflection about ergonomics, packaging and elderly, based on theoretical revision to base the theme and findings of empirical researches. Thus, it can be observed how ergonomics is relevant, being an underutilized knowledge in the area, but it should be increasingly applied in the diagnosis of problems in packaging and for the project of devices adequate to user needs, especially the elderly.
\end{abstract}

Keywords: elderly; packaging; ergonomics. 


\section{Introdução}

Idosos representam mais de $10 \%$ da população brasileira (BRASIL, 2013) e são um público em crescimento, o aumento da expectativa de vida reflete em um maior número de cidadãos atingindo a terceira idade. Não sendo exclusividade do Brasil, mas sim um fenômeno que vem sendo identificado no mundo todo (WORLD HEALTH ORGANIZATION, 2016), o crescimento da população idosa se constitui um desafio no sentido de garantir condições de vida adequadas para esse grupo de habitantes cada vez mais expressivo (NOWAK, 2006).

A atenção ao idoso se faz necessária visto que com o processo de envelhecimento até mesmo a realização de tarefas simples torna-se uma barreira para o bem-estar desses indivíduos. Com o avançar da idade funcionalidades importantes são perdidas, o que interfere de maneira significativa no desempenho de atividades comuns do dia-a-dia (CAIXETA; FERREIRA, 2009).

Design e ergonomia se inserem nessa questão fornecendo projetos que compreendam as diferenças funcionais entre os públicos de diferentes faixas etárias. Desse modo, as capacidades e limitações da população idosa devem ser entendidas e contabilizadas no processo de design e na pesquisa ergonômica para garantir que este segmento da população possa interagir com produtos e sistemas de forma segura, eficiente e efetiva (BOOT et al., 2012). Nowak (2006) entende que a ergonomia não só proporciona a este grupo de pessoas as facilidades para viver de forma independente, mas também contribui para o aumento do seu conforto e muitas vezes os impedem de sofrer acidentes.

Contudo, muitas vezes as necessidades dos idosos não são assimiladas ao projetar dispositivos. Designers e outros projetistas tendem a confiar em diretrizes de acessibilidade ou presunções comuns das necessidades e limitações dos usuários (HIGGINS; GLASGOW, 2012). Ou seja, em muitas situações não se tem conhecimento suficiente sobre o usuário idoso, o que ocasiona projetos que nem sempre são adequados para tal público.

Embalagens são exemplos de produtos que nem sempre se mostram adequados aos idosos. Zunjic (2011) afirma que o declínio das habilidades físicas e mentais dos idosos ocasionam dificuldade na abertura de embalagens. A capacidade de abertura de uma embalagem se tornou um problema com o envelhecimento da população (YOXALL et al., 2010a), uma vez que o processo natural de envelhecimento resulta, entre outras coisas, em perda de força, destreza e cognição, além da probabilidade do idoso viver com alguma doença crônica (YOXALL; BELL; WALTON, 2014), o que interfere diretamente na utilização de produtos como embalagens.

O insucesso na utilização de embalagens pode gerar uma série de prejuízos a quem as utiliza. Zunjic (2011) sustenta que a maioria das pessoas já teve uma experiência ruim com embalagens que pode ter ocasionado uma lesão. No Brasil, mais de $5 \%$ os acidentes de consumo ocorrem em função da manipulação de embalagens (INMETRO, 2016), sendo um produto potencialmente perigoso. Não apenas prejuízos físicos (como cortes e outros machucados) que embalagens podem vir a acarretar, problemas na interação com esses produtos pode gerar frustação e outros sentimentos negativos nos usuários (SUDBURY-RILEY, 2014), além de privação ao acesso de seus conteúdos, especialmente no caso de embalagens alimentícias, restringindo a aquisição de nutrientes importantes contidos nesses pacotes, visto que eles são necessários para otimização da saúde de muitos indivíduos, especialmente no caso de idosos (BELL; TAPSELL; WALTON, 2017). 
Dessa forma, o presente artigo propõe uma reflexão sobre a relação entre embalagens e ergonomia, procurando evidenciar como hoje a ergonomia não tem sido amplamente utilizada no desenvolvimento de embalagens e como ela poderia, a partir de seus dispositivos, vir a auxiliar no design de produtos mais compatíveis com os usuários, atentando para os indivíduos idosos.

\section{Design para o Envelhecimento}

O envelhecimento é implacável sobre o corpo humano. Com o passar dos anos, uma série de mudanças, de cunho morfológico e funcional, recaem sob os indivíduos, diminuindo a capacidade corporal em suprir a demanda necessária para manter uma vida com saúde (PERRACINI; FLÓ; GUERRA, 2009). Com o processo de envelhecimento, o organismo vai perdendo sua habilidade de se adaptar as diferentes situações, sendo mais suscetível a fatores de estresse, físicos e ambientais (SPIRDUSO, 2005).

O declínio físico é uma das dimensões mais perceptíveis do envelhecimento, esta impõe uma série de restrições ao viver dos sujeitos, que pode levar a uma perda da sensação de controle sobre a sua própria vida, tornando os idosos ainda mais vulneráveis (SPIRDUSO, 2005). Estudos apontaram que senescentes percebem a independência como parâmetro principal que indica seu estado de satisfação com a vida (NOWAK, 2006).

Um fator determinante no período que um idoso é capaz de viver por conta própria é a sua capacidade em lidar de forma autônoma com produtos do dia-a-dia. Contudo, essa habilidade não depende somente do idoso, mas também do design adequado dos produtos que o cercam. Desse modo, produtos projetados para este grupo em especial os ajudam a permanecer autossuficientes por mais tempo (DAAMS, 2006).

Contudo, de acordo com Kose (2006), nem sempre existem produtos pensados para esse público. Tradicionalmente os designers tendem a projetar considerando estatísticas de parâmetros médios populacionais, sem abranger necessariamente os idosos. $\mathrm{O}$ autor defende que muitas vezes há um equívoco quanto as necessidades dos idosos, as quais não podem ser equiparadas nem a dita "média" e nem a pessoas com deficiência. Isso torna-se ainda mais relevante mediante a atual estrutura populacional, onde os idosos já não representam mais uma minoria, mas uma parcela significativa da sociedade. Para Fisk et al. (2009), em alguns casos, designers incorporam - até mesmo de modo inconsciente - complexidade, ambiguidade e inconsistência nos dispositivos, interfaces e instruções, criando desequilíbrios entre as demandas impostas pelos produtos e os recursos mentais e físicos que o usuário dispõe.

Se algo é projetado para ser usado por idosos, esse público deve poder ver os recursos e componentes do sistema, ouvir qualquer informação auditiva que seja apresentada e manipular as partes componentes no tempo e com a precisão necessária para operar o sistema de forma adequada. Embora isso possa parecer uma informação óbvia, existem inúmeros produtos que não foram projetados com o usuário sênior em mente. Talvez não seja tão óbvio porque os projetistas precisam ter orientações específicas sobre mudanças relacionadas a idade nessas habilidades para poderem projetar produtos adequadamente (FISK et al., 2009).

Desse modo, torna-se indispensável conhecer o idoso, suas características e necessidades para que seja projetado um dispositivo o qual o usuário seja apto a utilizar (FISK et al., 2009). Por exemplo, mesmo que um produto não seja especialmente destinado aos idosos, um designer deve perceber que a força física varia muito entre os indivíduos e que os produtos destinados ao 
público em geral serão usados por pessoas diferentes, variando daqueles que são quase incapazes de exercer qualquer força, como é o caso dos doentes e idosos, para aqueles com mais de três vezes a força média, como com os homens jovens, saudáveis e bem treinados. Muitas pessoas pertencem a categorias com força muscular relativamente fraca e a falta de informações sobre as características e habilidades desses grupos é notável (DAAMS, 2006).

Higgins e Glasgow (2012) defendem que a criação de dispositivos utilizáveis por idosos requer uma base cientifica sólida, a partir de conhecimentos de algumas áreas, dentre elas, a ergonomia. A abordagem da ergonomia envolve o uso de conhecimento científico sobre as capacidades e limitações das pessoas para criar projetos com base em pontos fortes e capacidades, protegendo contra limitações. A idade traz muitas capacidades, como habilidade verbal, experiência e uma ampla base de conhecimento. No entanto, existem limitações associadas à percepção, cognição e controle de movimentos que ficam mais evidentes com a idade. É importante tomar consciência dessas limitações (FISK et al., 2009).

Sendo assim, ergonomia (ou fatores humanos) são uma ferramenta que fornece à esse grupo de pessoas meios para viver de forma independente, além de contribuir para o aumento do conforto de vida, muitas vezes evitando a ocorrência de acidentes perigosos (NOWAK, 2006).

\section{A Ergonomia no Design de Embalagens}

A ergonomia desempenha um papel importante no projeto de artefatos. Também chamada de fatores humanos, é a área de conhecimento que se preocupa em compreender as interações entre humanos e outros elementos de um sistema, com a finalidade de otimizar o bemestar humano e o desempenho geral do sistema, atuando sobre diversos elementos para torná-los compatíveis com as necessidades, habilidades e limitações das pessoas (INTERNATIONAL ERGONOMICS ASSOCIATION, 2018).

A ergonomia pode fornecer insumos importantes para o desenvolvimento de produtos, especialmente com a finalidade de torná-los adequados às capacidades dos seres humanos, contudo ela é muitas vezes subutilizada quando se trata de embalagens. Mesmo sendo produtos comuns e amplamente utilizados, poucas embalagens possuem características ergonômicas. Como resultado, há toda uma gama de problemas que sobrecarregam o usuário, os quais se manifestam por meio de insatisfação, frustração, ferimentos e abandono do produto por parte do consumidor (ZUNJIC, 2011). Hancock, Fisk e Rogers (2001) defendem que por serem considerados produtos familiares para a população em geral, designers de produto assumem que muitas embalagens são simples de utilizar e testes de usabilidade durante a fase de projeto, por exemplo, não são utilizados com muita frequência.

Assim, não são contabilizadas as características de determinados públicos, em especial aqueles em situação de vulnerabilidade, no projeto de tais invólucros (ZUNJIC, 2011). De acordo com Heiniö et al. (2006), do ponto de vista do usuário, há vários fatores que possivelmente influenciam na facilidade de abrir embalagens. Estas são a redução na força da mão, sensibilidade, destreza e preensão manual, destro ou canhoto, dificuldades de coordenação, tremores, dor, capacidade visual e cognitiva.

\subsection{Aspectos da Ergonomia no Projeto Físico de Embalagens}

A seguir são pontuadas algumas configurações de embalagens que devem levar em conta a ergonomia no momento que são concebidas, dentre eles os sistemas de fechamento, a 
capacidade de abertura, as dimensões, o peso e a textura.

Um sistema de fechamento considerado satisfatório deve ter boa relação com o recipiente que está fechando para maximizar o aproveitamento do produto pelo usuário. Dentre diversas características para um bom sistema de fechamento, destaca-se a qualidade de ser facilmente usado. O fechamento pode ser o melhor disponível para o produto e a linha de embalagem, mas se os consumidores encontrarem dificuldades no uso, provavelmente deixarão de utilizar esse produto. É preciso que seja verificado quem utilizará esses sistema, visto que consumidores recorrentes do produto podem ter diferentes capacidades (visão reduzida, deficiências motoras nos membros, perda de memória, etc.) ou podem incluir crianças - isso é particularmente importante em termos de embalagens child-resistant (THEOBALD, 2006a).

A capacidade de abertura (openability) pode ser definida como a aptidão para abrir dispositivos de fechamento de embalagens dentro de um prazo razoável, utilizando uma ferramenta (onde indicada e apropriada), com risco mínimo de lesão aos consumidores. Alguns fatores, com relação a restrições físicas, influenciam a capacidade de abertura de embalagens, como idade, força, funções motoras, deficiências e outros (WINDER, 2006). Outro problema relacionado a capacidade de abertura é saber como a mesma deve ser realizada. Geralmente, os usuários não conseguem determinar onde começar a abrir um pacote. A principal razão para isso é que em muitos casos não existem controles visíveis na embalagem, que poderiam ser usados para abertura (ZUNJIC, 2011).

Quanto as dimensões, elas devem obedecer às características antropométricas femininas e masculinas. Visto que os seres humanos interagem com as embalagens com as mãos, é preciso conceber embalagens adequadas as características e dimensões antropométricas da mão. Quando a embalagem é de dimensões reduzidas, a embalagem deve ser projetada de forma que o 950 percentil dos consumidores possa abrir a embalagem com sucesso. Se a embalagem tiver grandes dimensões, os projetistas devem levar em conta o 50 percentil da população de usuários (ZUNJIC, 2011). Diferentes dimensões também influenciam na força que precisa ser realizada para abrir uma embalagem, isso ocorre especialmente no caso de embalagens com tampa de rosca (CRAWFORD; WANIBE; NAYAK, 2002).

O peso de uma embalagem depende em grande parte do próprio produto que ela contém. Se um produto for pesado, o conforto pode ser aumentado com a instalação de uma alça ou uma pega, o que facilitará o manuseio e o transporte (ZUNJIC, 2011).

A textura da embalagem também deve suportar o fácil manuseio. Em alguns casos, uma superfície rugosa pode aumentar o atrito durante o contato entre a mão e a embalagem, o que facilita a abertura. A textura também pode ser usada como um método de codificação de embalagens, particularmente importante para identificação por pessoas com deficiências visuais (ZUNJIC, 2011). Ela também pode ser algo importante no contexto de uso do produto. Algumas embalagens são frequentemente usadas na cozinha ou no banheiro e, portanto, os usuários muitas vezes as utilizam com as mãos molhadas ou oleosas. A presença de óleo ou água nas mãos pode tornar-se um problema na capacidade de manipulação de algumas embalagens, especialmente para usuários debilitados (CANTY; LEWIS; YOXALL, 2013). 


\section{Embalagens e Idosos}

A população idosa está em constante crescimento, com isso a facilidade com que as embalagens podem ser abertas está se tornando um problema muito maior, já que pode ter impacto na qualidade de vida dos indivíduos. As deficiências que invariavelmente acompanham a idade, como perda de acuidade visual, articulações artríticas, perda de força e, em particular, falta de torque ou preensão manual, além de outras, criam uma perspectiva diferente sobre as características das embalagens, para que elas funcionem corretamente (THEOBALD, 2006b). Os idosos compreendem uma grande e crescente proporção da população, é importante que eles consigam atender a si mesmos o máximo possível, tendo as embalagens um papel importante no preparo de alimentos, na higiene pessoal e entre outras situações. Assim, é fundamental que a embalagem seja fácil, segura e conveniente de usar (BERNS, 1981).

Pesquisa realizada por Hancock, Fisk e Rogers (2001) evidenciou que idosos possuem diversas dificuldades em relação ao uso de embalagens, contudo, dificuldades na abertura e manipulação de produtos foi uma queixa de quase $95 \%$ da amostra de idosos participantes, demostrando como a como a configuração física dos invólucros é algo bastante problemático para tal população.

\section{Método}

Nos tópicos anteriores foram apresentados autores que defendem que o projeto de embalagens, muitas vezes, é inconsistente com as capacidades de pessoas idosas. Para evidenciar como a questão embalagem-idoso vem sendo demonstrada empiricamente, o presente trabalho procurou reunir pesquisas relevantes que tratam dessa interação. Tais pesquisas foram obtidas por meio de uma revisão sistemática de literatura realizada previamente pelos autores. A busca foi feita em bases de dados internacionais (Scopus, Web of Science e ProQuest) em outubro/2017 e atualizada em janeiro/2018, a partir de termos relacionados a idosos, embalagens e avaliação. Foram selecionados apenas artigos publicados em periódicos entre 2007 e 2017, primando por trabalhos que atentaram para aspectos relacionados a função manual dos usuários, por isso pesquisas focadas apenas em atributos como legibilidade ou cognição, mesmo que relevantes, foram excluídas do portfólio final de referências obtido pela revisão sistemática.

\section{Resultados}

É notório a necessidade da integração dos conhecimentos da ergonomia para o desenvolvimento de embalagens que sejam manipuladas facilmente e não causem prejuízos, especialmente para o público idoso. Nos últimos anos, diferentes grupos de pesquisa pelo mundo estão promovendo estudos a fim de atestar a inconsistência de diferentes tipos de embalagens com as características dos idosos.

No Quadro 1 constam pesquisas encontradas por meio de uma revisão sistemática que tratam da temática. Assim é possível conhecer os problemas decorrentes da interação que estão sendo identificados, as caraterísticas físicas do idoso apontadas nas pesquisas que estão relacionadas aos problemas, as categorias de embalagem analisadas e as suas características problemáticas. 
Quadro 1 - Pesquisas que abordam a interação idoso-embalagem

\begin{tabular}{|c|c|c|c|c|}
\hline Referência & $\begin{array}{c}\text { Problemas } \\
\text { na interação }\end{array}$ & $\begin{array}{l}\text { Caraterísticas } \\
\text { do idoso }\end{array}$ & $\begin{array}{l}\text { Categoria das } \\
\text { embalagens }\end{array}$ & $\begin{array}{l}\text { Características dos } \\
\text { produtos }\end{array}$ \\
\hline (LEWIS et al.,2007) & Força insuficiente & Baixa força manual & Alimento & Não especificadas \\
\hline $\begin{array}{c}\text { (CARSE; } \\
\text { THOMSON; } \\
\text { STANSFIELD, 2010) }\end{array}$ & $\begin{array}{l}\text { - Dificuldade de abertura } \\
\text { - Util. de ferramentas } \\
\text { - Desconforto/dor }\end{array}$ & Não especificadas. & $\begin{array}{l}\text { Alimentos } \\
\text { Medicamento } \\
\text { Limpeza }\end{array}$ & Não especificadas \\
\hline $\begin{array}{l}\text { (YOXALL et al., } \\
\text { 2010b) }\end{array}$ & $\begin{array}{l}\text { - Força insuficiente } \\
\text { - Esforço por repetição } \\
\text { - Desconforto/dor }\end{array}$ & $\begin{array}{l}\text { - Baixa força manual } \\
\text { - Dimensão da mão } \\
\text { (mulheres) }\end{array}$ & $\begin{array}{l}\text { Alimento } \\
\text { Higiene }\end{array}$ & $\begin{array}{l}\text { - Material de garrafa } \\
\text { - Forma da garrafa } \\
\text { - Combinação de bicos }\end{array}$ \\
\hline $\begin{array}{c}\text { (CARSE; } \\
\text { THOMSON; } \\
\text { STANSFIELD, 2011) }\end{array}$ & $\begin{array}{l}\text { - Forças insuficientes } \\
\text { - Dificuldade de abertura } \\
\text { - Lentidão }\end{array}$ & $\begin{array}{l}\text { - Baixa força manual } \\
\text { - Medo de lesão }\end{array}$ & Alimento & Não especificadas \\
\hline $\begin{array}{l}\text { (MARKS et al., } \\
\text { 2012) }\end{array}$ & $\begin{array}{l}\text { - Dificuldade de abertura } \\
\text { - Força Insuficiente }\end{array}$ & $\begin{array}{l}\text { - Baixa força manual } \\
\text { - Patologias }\end{array}$ & Alimento & $\begin{array}{l}\text { - Tamanho da aba } \\
\text { - Material da aba } \\
\text { - Formato da aba } \\
\text { - Mecanismo complexo }\end{array}$ \\
\hline $\begin{array}{l}\text { (MÜHLFELD et al., } \\
\text { 2012) }\end{array}$ & $\begin{array}{l}\text { - Forças insuficientes } \\
\text { - Desconforto/dor }\end{array}$ & $\begin{array}{l}\text { - Baixa força manual } \\
\text { - Baixa destreza } \\
\text { - Baixa acuidade visual } \\
\text { - Patologias }\end{array}$ & Medicamento & $\begin{array}{l}\text { - Tamanho da cavidade } \\
\text { - Tamanho da aba } \\
\text { - Cor da aba } \\
\text { - Formato da aba } \\
\text { - Material da película }\end{array}$ \\
\hline $\begin{array}{l}\text { (CANTY; LEWIS; } \\
\text { YOXALL, 2013) }\end{array}$ & $\begin{array}{l}\text { - Dificuldade de abertura } \\
\text { - Derramamento do } \\
\text { produto }\end{array}$ & Baixa destreza & Alimento & $\begin{array}{l}\text { - Textura da aba } \\
\text { - Tamanho da aba } \\
\text { - Formato da aba }\end{array}$ \\
\hline (YEN et al., 2013) & $\begin{array}{l}\text { - Dificuldade de abertura } \\
\text { - Desconforto/Dor } \\
\text { - Forças insuficientes }\end{array}$ & $\begin{array}{l}\text { - Baixa força manual } \\
\text { - Sensibilidade } \\
\text { - Baixa destreza } \\
\text { - Patologias }\end{array}$ & Alimento & $\begin{array}{l}\text { - Altura das tampas } \\
\text { - Diâmetro das tampas } \\
\text { - Formato das tampas } \\
\text { - Textura das tampas }\end{array}$ \\
\hline $\begin{array}{l}\text { (SORMUNEN; } \\
\text { NEVALA; } \\
\text { SIPILÄ, 2014) }\end{array}$ & $\begin{array}{l}\text { - Forças insuficientes } \\
\text { - Difícil compreensão do } \\
\text { mecanismo de abertura } \\
\text { - Lentidão } \\
\text { - Desconforto/dor }\end{array}$ & $\begin{array}{l}\text { - Restrição motora } \\
\text { - Baixa amplitude de } \\
\text { movimento } \\
\text { - Baixa destreza } \\
\text { - Deficiência cognitiva } \\
\text { - Baixa força manual }\end{array}$ & Medicamento & $\begin{array}{l}\text { - Mecanismo complexo } \\
\text { - Diâmetro }\end{array}$ \\
\hline $\begin{array}{c}\text { (HENSLER; } \\
\text { HERREN; MARKS, } \\
\text { 2015) }\end{array}$ & $\begin{array}{l}\text { - Força Insuficiente } \\
\text { - Difícil acesso ao } \\
\text { mecanismo de abertura }\end{array}$ & $\begin{array}{l}\text { - Baixa força manual } \\
\text { - Dificuldade na } \\
\text { preensão digital } \\
\text { - Patologias }\end{array}$ & Alimento & $\begin{array}{l}\text { - Tamanho da aba } \\
\text { - Separação da aba } \\
\text { superior e inferior } \\
\text { - Formato da aba }\end{array}$ \\
\hline $\begin{array}{c}\text { (BONFIM; } \\
\text { MEDOLA; } \\
\text { PASCHOARELLI, } \\
\text { 2016) } \\
\end{array}$ & $\begin{array}{l}\text { - Dificuldade de abertura } \\
\text { - Forças insuficientes } \\
\text { - Téc. de preensão digital }\end{array}$ & Baixa força manual & Higiene & $\begin{array}{l}\text { - Mecanismo complexo } \\
\text { - Diâmetro da tampa } \\
\text { - Textura da tampa } \\
\text { - Formato da Tampa }\end{array}$ \\
\hline $\begin{array}{l}\text { (BRAUN-MUNKER; } \\
\text { ECKER, 2016) }\end{array}$ & Dificuldade de abertura & Não especificadas. & Medicamento & $\begin{array}{l}\text { - Tamanho da cavidade } \\
\text { - Opacidade do material }\end{array}$ \\
\hline $\begin{array}{l}\text { (BELL; WALTON; } \\
\text { TAPSELL, 2016) }\end{array}$ & $\begin{array}{l}\text { - Dificuldade de abertura } \\
\text { - Forças insuficientes }\end{array}$ & $\begin{array}{l}\text { - Baixa força manual } \\
\text { - Bem-estar físico, } \\
\text { social e mental } \\
\text { - Baixa destreza }\end{array}$ & Alimento & - Tamanho da aba \\
\hline (YEN et al., 2016) & $\begin{array}{l}\text { - Dificuldade de abertura } \\
\text { - Desconforto/dor } \\
\text { - Forças insuficientes }\end{array}$ & $\begin{array}{l}\text { - Baixa força manual } \\
\text { - Patologias }\end{array}$ & Alimento & $\begin{array}{l}\text { - Diâmetro da tampa } \\
\text { - Altura da tampa } \\
\text { - Formato da tampa } \\
\text { - Textura da tampa }\end{array}$ \\
\hline
\end{tabular}




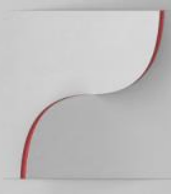

\begin{tabular}{|c|c|c|c|c|}
\hline $\begin{array}{c}\text { (WENK et al., } \\
\text { 2016) }\end{array}$ & $\begin{array}{l}\text { - Dificuldade de abertura } \\
\text { - Forças insuficientes } \\
\text { - Desconforto/dor } \\
\text { - Derramamento do } \\
\text { produto } \\
\text { - Lesões }\end{array}$ & $\begin{array}{l}\text { - Baixa força manual } \\
\text { - Baixa destreza } \\
\text { - Sensibilidade tátil } \\
\text { reduzida } \\
\text { - Deficiência cognitiva } \\
\text { - Baixa acuidade visual }\end{array}$ & Alimento & $\begin{array}{l}\text { - Diâmetro da tampa } \\
\text { - Selos de difícil } \\
\text { rompimento } \\
\text { - Tamanho da aba } \\
\text { - Arestas cortantes } \\
\text { - Mecanismo complexo }\end{array}$ \\
\hline $\begin{array}{l}\text { (BELL; WALTON; } \\
\text { YOXALL, 2017) }\end{array}$ & $\begin{array}{l}\text { - Dificuldade de abertura } \\
\text { - Forças insuficientes }\end{array}$ & $\begin{array}{l}\text { - Baixa força manual } \\
\text { - Baixa destreza }\end{array}$ & Alimento & - Mecanismo complexo \\
\hline
\end{tabular}

Fonte: Os autores, 2018.

O Quadro 1 apresenta resumidamente alguns achados das pesquisas reunidas. Destacamse os vários problemas na interação-idoso embalagem e a sua relação com características dos idosos e atributos problemáticos de embalagens.

A interação recorrentemente tratada pelas pesquisas é a abertura das embalagens. Dessa forma, o problema na interação usuário-embalagem que aparece com mais frequência é a dificuldade de abertura. Contudo, alguns estudos vão além e apontam razões mais especificas para o insucesso da interação, entre eles força(s) insuficiente(s) para a manipulação das embalagens, a presença de desconforto/dor na utilização dos produtos, lentidão na realização da tarefa, derramamento do produto, o perigo de ocorrer lesões na utilização da embalagem, técnicas de preensão digital utilizadas, difícil acesso ao mecanismo de abertura da embalagem e compreensão do mesmo.

Os problemas da interação são geralmente ligados a características dos usuários que não são contempladas pelo design do produto, tornando configurações do produto problemáticas para os indivíduos. De acordo com os artigos, as características dos idosos que influenciam na interação com embalagens são principalmente baixa força manual e baixa destreza, sendo essas características assinaladas em mais trabalhos. Além dessas, são mencionadas também a presença de patologias nas mãos (como artrite reumatoide e outras), a dimensão das mãos (com relação ao tamanho das embalagens), a sensibilidade tátil, baixa amplitude de movimento do membro superior, dificuldade em realizar movimentos de preensão digital e restrição motora. Outras questões não relacionadas com as mãos também foram mencionadas como bem-estar, deficiência cognitiva, baixa acuidade visual e medo de sofrer lesão durante a atividade.

As características que são problemas nos produtos variaram de acordo com o tipo de embalagem. Para os frascos que necessitam ser apertados para serem utilizados, os problemas residem no material no qual são confeccionados, na forma dos frascos e os bicos neles utilizados. Já para embalagens que contêm abas que necessitam ser puxadas para a remoção de películas (como em copos de iogurte, pacotes de queijo e alguns blisters) tamanho, material, formato, textura e cor necessitam ser melhor pensados, sendo até mesmo a separação entre a aba superior e inferior um problema. Nas embalagens com tampas de rosca são descritas problemáticas a altura, diâmetro, formato (lateral e superior) e textura. Para os blisters, além dos problemas relacionados às abas, também se apresentam como problemas o tamanho das cavidades onde estão os comprimidos e o material da película que reveste o blister. Outras características mais gerais são pontuadas, como mecanismos complexos, arestas cortantes e selos de difícil rompimento. 


\section{Discussão}

O quadro apresentado fornece uma ideia do que os estudos estão verificando de problemas que idosos tem com embalagens e como isso se relaciona com características do envelhecimento e o design de certas embalagens.

São vários os problemas na interação idoso-embalagem que puderam ser identificados pelos estudos, demostrando uma problemática real e que precisa ser tratada pelo viés ergonômico. Ainda que não esgotem a questão, os estudos já realizados demonstram que é possível, a partir da identificação dos problemas, constatar configurações nas embalagens que se tornam um problema ao envelhecer, fornecendo informações para o novo design das mesmas.

Os problemas detectados reforçam o que já é descrito na literatura, que as falhas na interação ocorrem em função do que se é exigido na manipulação de embalagens não ser compatível com as condições que os idosos podem cumprir, especialmente em relação as forças necessárias.

Também pode ser verificado que problemas na interação com embalagens são capazes de gerar experiências ruins, como a presença de desconforto e dor, a possibilidade de ocorrência de lesões, o derramamento dos conteúdos, a difícil compreensão dos mecanismos para abertura, lentidão no processo de abertura, o esforço por repetição para conseguir utilizar o produto e a dificuldade de abertura de modo geral. Assim, reforça-se o que é afirmado por Zunjic (2011) e Sudbury-Riley (2014) quando falam das impressões negativas que as embalagens podem gerar nos usuários.

Sobre as características dos idosos, os estudos apontaram aquelas que já são mencionadas na literatura por causarem interferência na interação, são restrições que já se esperam ser identificadas nos idosos. Contudo, patologias relacionadas a função manual (como artrite reumatoide), que são bastante recorrentes em idosos, também figuraram nos estudos. Isso é algo importante, visto que o idoso saudável já apresenta acometimentos, com a presença de patologias, as condições passam a ser muito mais severas, o que exige atenção ainda mais especial nos projetos das embalagens, visto que as características do idoso podem ter maior interferência na interação nesses casos.

Ainda sobre as características dos idosos, também foram identidades condições que não são necessariamente atributos, mas se relacionam com a situação do indivíduo e suas experiências prévias. O estudo de Bell, Walton e Tapsell (2016) assinalou que o bem-estar do idoso pode influenciar na sua interação com as embalagens, nesse caso os idosos estavam hospitalizados, algo que pode alterar o seu desempenho. Carse, Thomson e Stansfield (2011) relataram o medo por lesão como uma característica influente na interação, o que pode sugerir que o usuário já teve experiências ruins com embalagem e tem receio que isso possa ocorrer novamente, comprometendo as interações futuras.

Quanto as configurações das embalagens, entende-se que as características consideradas problemáticas podem ser fruto de escolhas projetuais equivocadas, em relação aos materiais utilizados, o dimensionamento dos produtos, o formato dos dispositivos, as texturas aplicadas e entre outros atributos fundamentais que possivelmente não foram corretamente projetas por desconhecimento das necessidades dos usuários ou mesmo a falta de testes prévios. 


\section{Considerações Finais}

As pessoas estão vivendo cada vez mais, estão tornando-se mais ativas em idade avançada e permanecendo em suas casas mais tempo antes de serem assistidas (FISK et al., 2009). Portanto, os artefatos que as cercam contribuem, quando bem projetados, para que esse indivíduo seja autônomo, demostrando como produtos são parte importante no dia-a-dia das pessoas.

A questão que envolve idosos e embalagens ainda se torna mais relevante mediante da crescente expansão da terceira idade, que carece de produtos que satisfaçam suas necessidades. Uma embalagem bem projetada, que não tem impacto negativo sobre o usuário, pode influenciar também na maior aceitação do produto em detrimento de outros que não causam uma boa experiência. Sudbury-Riley (2014) defende que, diferente de outros grupos em situação de vulnerabilidade, o público idoso tende a não aceitar serviços ruins, optando por outras marcas e produtos quando algo não responde a suas expectativas

A partir da reflexão aqui proposta, entende-se que a questão que envolve o projeto de produtos para idosos, em especial embalagens, necessita cada vez mais da interferência do conhecimento ergonômico a fim de conceber produtos de fácil acesso e utilização. Fica evidente então a importância de utilizar a ergonomia tanto no diagnóstico dos problemas das embalagens atuais, como também fornecendo subsídios para o projeto de novos produtos com configurações mais compatíveis com as capacidades dos usuários.

Carus et al. (2006) apresenta um exemplo: ao estudar as ações específicas utilizadas no manuseio e abertura de embalagens, medindo as forças de torque e preensão que os consumidores podem aplicar durantes essas ações, é possível posteriormente utilizar esses valores como limites de projeto para as forças de vedação de embalagens, podendo-se prever que o usuário mais fraco poderá abrir a embalagem.

Estudos como os apresentados no Quadro 1 se tornam ainda mais relevantes visto que alguns autores defendem que os designers de embalagens não estão habituados a incorporar os dados referentes aos fatores humanos do público idoso no projeto de embalagens (CARSE; THOMSON; STANSFIELD, 2010), o que salienta a importância da academia para chamar atenção sobre a questão.

No que tange a pesquisa em ergonomia e embalagens, apesar de ser uma área em desenvolvimento, resultados interessantes já foram alcançados, em relação aos principais problemas na interação que ocorrem, as características dos idosos e os atributos problemáticos encontrados nas embalagens analisadas. É importante destacar também, que algumas das pesquisas apresentadas no Quadro 1 foram realizadas em parceria com a indústria, o que mostra que já existe uma sensibilização do mercado em relação a essa temática, demonstrando que há espaço para que a questão avance cada vez mais.

Dessa forma, é preciso dar continuidade nas pesquisas que abordam a relação de idosos e embalagens, de modo que sejam exploradas ainda mais embalagens que podem vir a possuir características problemáticas para esse público. Espera-se que os estudos se aprofundem cada vez mais no conhecimento das características do usuário sênior, demostrando a relevância do conhecimento ergonômico no projeto de produtos. Assim, existe a expectativa que designers criem novas soluções para abertura de embalagens com caraterísticas simples, eficientes e que atendam o público em geral incluindo os usuários idosos. 


\section{Referências}

BELL, A. F.; TAPSELL, L. C.; WALTON, K. L. Food Packaging and Older Adults. In: RAATS, M. M.; GROOT, L. C. P. G. M. DE; ASSELT, D. VAN (Eds.). . Food for the Aging Population. 2. ed. Duxford: Woodhead Publishing, 2017. p. 349-370.

BELL, A. F.; WALTON, K. L.; TAPSELL, L. C. Easy to open? Exploring the "openability" of hospital food and beverage packaging by older adults. Appetite, v. 98, p. 125-132, 2016.

BELL, A.; WALTON, K.; YOXALL, A. Measure for Measure: Pack Performance versus Human Dexterity and Grip Strength. Packaging Technology and Science, v. 30, n. 4, p. 117-126, 2017.

BERNS, T. The handling of consumer packaging. Applied Ergonomics, v. 12, n. 3, p. 153-161, 1981.

BONFIM, G. H. C.; MEDOLA, F. O.; PASCHOARELLI, L. C. Correlation among cap design, gripping technique and age in the opening of squeeze-and-turn packages: A biomechanical study. International Journal of Industrial Ergonomics, v. 54, p. 178-183, 2016.

BOOT, W. R. et al. Design for Aging. In: SALVENDY, G. (Ed.). . Handbook of Human Factors and Ergonomics. 4. ed. Hoboken, New Jersey: John Wiley \& Sons, 2012. p. 1442-1471.

BRASIL. Estatuto do idoso. 3. ed. Brasília: Ministério da Saúde, 2013.

BRAUN-MUNKER, M.; ECKER, F. Ease of opening of blistered solid dosage forms in a senior citizens target group. INTERNATIONAL JOURNAL OF PHARMACEUTICS, v. 512, n. 2, SI, p. 412-415, 2016.

CAIXETA, G. C. D. S.; FERREIRA, A. Desempenho cognitivo e equilíbrio funcional em idosos. Revista Neurociencias, v. 17, n. 3, p. 202-208, 2009.

CANTY, L. A.; LEWIS, R.; YOXALL, A. Investigating openability of rigid plastic containers with peelable lids: The link between human strength and grip and opening forces. Proceedings of the Institution of Mechanical Engineers, Part C: Journal of Mechanical Engineering Science, v. 227, n. 5, p. 1056-1068, 2013.

CARSE, B.; THOMSON, A.; STANSFIELD, B. Use of biomechanical data in the Inclusive Design process: packaging design and the older adult. Journal of Engineering Design, v. 21, n. 2-3, p. 289-303, 2010.

CARSE, B.; THOMSON, A.; STANSFIELD, B. A novel device for evaluating forces during the dynamic jar opening action-Do older and younger adults do things differently? Medical Engineering and Physics, v. 33, n. 4, p. 521-525, 2011.

CARUS, D. A. et al. Development and validation of a technique to measure and compare the opening characteristics of tamper-evident bottle closures. Packaging Technology and Science, v. 19, n. 2, p. 105-118, 2006.

CRAWFORD, J. O.; WANIBE, E.; NAYAK, L. The interaction between lid diameter, height and shape on wrist torque exertion in younger and older adults. Ergonomics, v. 45, n. 13, p. 922-933, 1 out. 2002.

DAAMS, B. J. Force Exertion for (Consumer) Product Design: Problem Definition. In: KARWOWSKI, W. (Ed.). . International Encyclopedia of Ergonomics and Human Factors. 2. ed. Boca Raton, FL: CRC Press, 2006. p. 347-349.

FISK, A. D. et al. Designing for Older Adults: Principles and Creative Human Factors Approaches. 
2. ed. Boca Raton, Florida: CRC Press, 2009.

HANCOCK, H. E.; FISK, A. D.; ROGERS, W. A. Everyday products: Easy to use ... or not? Ergonomics in Design, v. 9, n. 4, p. 12-18, 2001.

HEINIÖ, R.-L. et al. Scientific background for the basis of an international standard for easy-toopen packages (EASYOPENPACK). Oslo: Nordic Innovation Centre, 2008.

HENSLER, S.; HERREN, D. B.; MARKS, M. New technical design of food packaging makes the opening process easier for patients with hand disorders. Applied Ergonomics, v. 50, p. 1-7, 2015.

HIGGINS, P. G.; GLASGOW, A. Development of guidelines for designing appliances for older persons. Work, v. 41, p. 333-339, 2012.

INMETRO. Sistema Inmetro de Monitoramento de Acidentes de Consumo. Disponível em: <http://www.inmetro.gov.br/consumidor/pdf/acidente-consumo-infografico-2016.pdf>. Acesso em: 7 nov. 2017.

INTERNATIONAL ERGONOMICS ASSOCIATION. Definition and Domains of Ergonomics. Disponível em: <http://www.iea.cc/whats/index.html>. Acesso em: 11 mar. 2018.

KOSE, S. Universal Design for the Aging. In: KARWOWSKI, W. (Ed.). . International Encyclopedia of Ergonomics and Human Factors. 2. ed. Boca Raton, FL: CRC Press, 2006. p. 227-230.

LEWIS, R. et al. Finger friction: Grip and opening packaging. Wear, v. 263, n. 7-12 SPEC. ISS., p. 1124-1132, 2007.

MARKS, M. et al. Packaging-A Problem for Patients with Hand Disorders? A Cross-sectional Study on the Forces Applied to Packaging Tear Tabs. Journal of Hand Therapy, v. 25, n. 4, p. 387-396, 2012.

MÜHLFELD, L. et al. Influence of blister package design on usability among older adults. International Journal of Clinical Pharmacy, v. 34, n. 4, p. 553-560, 2012.

NOWAK, E. Anthropometry for the Needs of the Elderly. In: KARWOWSKI, W. (Ed.). . International Encyclopedia of Ergonomics and Human Factors. 2. ed. Boca Raton, FL: CRC Press, 2006. p. 258265.

PERRACINI, M. R.; FLÓ, C. M.; GUERRA, R. O. Funcionalidade e Envelhecimento. In: PERRACINI, M. R.; FLÓ, C. M. (Eds.). . Funcionalidade e Envelhecimento. Rio de Janeiro: Guanabara Koogan, 2009. p. 557.

SORMUNEN, E.; NEVALA, N.; SIPILÄ, S. Critical factors in opening pharmaceutical packages: A Usability study among healthcare workers, women with rheumatoid arthritis and elderly women. Packaging Technology and Science, v. 27, n. 7, p. 559-576, 2014.

SPIRDUSO, W. W. Dimensões Físicas do Envelhecimento. Barueri, SP: Manole, 2005.

SUDBURY-RILEY, L. Unwrapping senior consumers' packaging experiences. Marketing Intelligence \& Planning, v. 32, n. 6, p. 666-686, 2014.

THEOBALD, N. Introduction. In: THEOBALD, N.; WINDER, B. (Eds.). . Packaging Closures and Sealing Systems. Oxford: Blackwell Publishing, 2006a. p. 1-35.

THEOBALD, N. Child resistance, tamper evidence and openability. In: THEOBALD, N.; WINDER, B. 
(Eds.). . Packaging Closures and Sealing Systems. Oxford: Blackwell Publishing, 2006b. p. 231-258.

WENK, S. et al. Evaluation of the Accessibility of Selected Packaging by Comparison of Quantitative Measurements of the Opening Forces and Qualitative Surveys through Focus Group Studies. Packaging Technology and Science, v. 29, n. 11, p. 559-570, 2016.

WINDER, B. The design of packaging closures. In: THEOBALD, N.; WINDER, B. (Eds.). . Packaging Closures and Sealing Systems. Oxford: Blackwell Publishing, 2006.

WORLD HEALTH ORGANIZATION. World health statistics 2016: monitoring health for the SDGs, sustainable development goals. Geneva: WHO Library Cataloguing-in-Publication Data, 2016.

YEN, W.-T. et al. Preference of lid design characteristics by older adults with limited hand function. Journal of Hand Therapy, v. 26, n. 3, p. 261-70; quiz 271, 2013.

YEN, W.-T. et al. Evaluation of jar lid design characteristics by older women with hand use limitations. Applied Ergonomics, v. 52, p. 177-184, 2016.

YOXALL, A. et al. How wide do you want the jar?: the effect on diameter for ease of opening for wide-mouth closures. Packaging Technology and Science, v. 23, p. 11-18, 2010a.

YOXALL, A. et al. Squeezability. Part 2: getting stuff out of a bottle. Proceedings of the Institution of Mechanical Engineers, v. 224, n. C6, p. 1261-1271, $2010 \mathrm{~b}$.

YOXALL, A.; BELL, A.; WALTON, K. Warning! : packaging can damage your health. (A. Yoxall, K. Christer, Eds.)Proceedings of the Second European Conference on Design 4 Health 2013. Anais...Sheffield: Sheffield Hallam University, 2014Disponível em: <http://shura.shu.ac.uk/8476/>

ZUNJIC, A. Ergonomics of Packaging. In: KARWOWSKI, W.; SOARES, M. M.; STANTON, N. A. (Eds.). . Human Factors and Ergonomics in Consumer Product Design: Uses and Applications. Boca Raton, FL: CRC Press, 2011. p. 101-123. 